\title{
How Long Tail and Trust Affect Online Shopping Behavior: An Extension to UTAUT2 Framework
}

\author{
Mahendra Singh* $^{*}$ \\ Yokohama National University \\ mahenrsingh@gmail.com \\ Yoshiki Matsui \\ Yokohama National University \\ ymatsui@ynu.ac.jp
}

\begin{abstract}
This research aims at understanding the effect of long tail and trust on the customer motivation behind online shopping use. In this research, we adopt the Extended Unified Theory of Acceptance and Use of Technology2 (UTAUT2) and expand with two additional constructs "long tail effect" and "trust" to understand whether these two key factors influence the customer motivation to choose online channels for shopping. Research was conducted in Japan for two product categories i.e. airline ticket and book. One is a physical product while the other is a service product. Both "Iong tail effect" and "trust" were found to have significant relationships with the intention to use, however, there were some differences between the two products, due to their inherent characteristics. Inclusion of both "Iong tail effect" and "trust" constructs to the existing UTAUT2 research framework is proposed for future research.
\end{abstract}

Keywords: Online Shopping, e-commerce, e-business, UTAUT2, Long Tail, Trust, Technology Acceptance

Citation: Singh, M. and Matsui, Y. (2017). "How Long Tail and Trust Affect Online Shopping Behavior: An Extension to UTAUT2 Framework," Pacific Asia Journal of the Association for Information Systems, 9(4), pp. 1-24. 


\section{Introduction}

With the development of Internet technologies and the ease of using them, the ways in which people are using the Internet is constantly expanding. The Internet helps people connect, as a channel of communication, information sharing, entertainment, and also as a vehicle for commercial buy and sell transactions (Swaminathan et al., 1999). This mechanism of using internet for buy and sell transactions is called by various names such as e-commerce, online shopping, internet shopping, and so forth. The adoption of the Internet for shopping has witnessed a rapid growth in the last two decades. This growth in online shopping can be attributed to reasons such as, an increase in the Internet penetration rate across the globe and the numerous benefits realized by the Internet users through online shopping. In general, people believe that the main motivation behind choosing online channels for shopping are lower price and increased convenience. However, there are many studies that suggest there are some other motivations behind choosing online channels for shopping, such as social influence, ease of use, and so forth. Even though there have been numerous research studies in the past, that have focused on understanding the user motivations behind online shopping, but still this basic question has not been adequately answered.

Before e-commerce came into existence, retailing was mainly conducted through physical stores that could only accommodate a limited number of stock keeping units (SKUs). However, through ecommerce, retailers can offer products for which customer demand has dropped over a period of time. These lower demand products collectively form a considerable amount of sales for online retailers; this phenomenon is called the long tail effect (LT). This results in a broader selection of product offerings for online shoppers because they can even purchase products usually not easily available at physical stores. LT is considered a prominent strength of e-commerce.

Online shopping is conducted remotely through the Internet in the absence of faceto-face interaction and carries various inherent risks associated with Internet network, such as data theft, virus attacks, online fraud, and so forth, which makes trust a very important requirement for users to conduct online shopping.

For analyzing technology acceptance among organizations and individual consumers, the extended unified theory of acceptance and use of technology (UTAUT2) framework is considered the latest framework. The UTAUT2 framework has seven constructs: performance expectancy, effort expectancy, social influence, facilitating conditions, hedonic motivation, price value, and habit. There have been many research studies in the past that have explored the importance of trust when it comes to the selection of online channels for shopping, but this is still not an explicit construct in the UTAUT2 framework.

The current research aims to understand whether LT and trust are also customer motivations behind online shopping use. For this research, two products-airline tickets and books were selected and the study was conducted in Japan. These two products were selected because they are expected to have different product characteristics. Books represent a physical product while airline tickets represent a service product. In recent years, both of these products have been popular on online channels.

The motivation behind the current study is the reason that although various theories and frameworks related to e-commerce and technology acceptance were developed during the early years of evolution of ecommerce, and many impactful papers were published during that time, but with the continued evolution of new Internet technologies that have brought disruptive innovations to businesses, the focus of researchers has moved to various other 
interesting topics, such as big data, social networks, artificial intelligence, and so forth, leaving this basic question not fully answered (Singh \& Matsui, 2015). If it is possible to compile all the motivations behind online shopping in a single framework, then it would be beneficial to the organizations in allocating their resources to get the optimized results from this new additional channel of sales. Organizations would be able to make the informed decisions to improve the online shopping adoption rate.

For this purpose, the latest research framework, UTAUT2, is selected, and additional constructs of trust and LT are tested in this research. LT has been discussed by researchers in the past as a specific characteristic of online shopping, but it is difficult to find any research conducted in the past to understand if $L T$ could be a motivation factor behind the adoption of online shopping. Similarly, there has been many studies on trust, but it is not yet an explicit part of the latest research framework. The current research proposes the addition of these two constructs in the existing UTAUT2 framework for future research. The current research also conducts a comparative study between a physical product and a service product to understand if the motivations behind online shopping adoption varies depending on the product specific characteristics.

\section{Theoretical Background}

There have been many models and frameworks that have tried to explain the reasons behind the adoption and diffusion of technology. The Unified theory of acceptance and use of technology (UTAUT), which is one of the most recent frameworks, has evolved from the synthesis of eight predecessor research models: the theory of reasoned action (TRA), the technology acceptance model (TAM), the motivational model (MM), the theory of planned behavior (TPB), a model combining the technology acceptance model and the theory of planned behavior (C-TAM-TPB), the model of PC utilization (MPCU), the innovation diffusion theory (IDT), and the social cognitive theory (SCT). UTAUT was formulated with four core determinants of intention and usage, and after testing, it was found to outperform the eight individual models (Venkatesh et al., 2003).

UTAUT originally had four constructsperformance expectancy, effort expectancy, social influence, and facilitating condition. It has been mainly used for explaining the reasons behind technology adoption by organizations. However, hedonic motivation, price value, and habit were subsequently added to the UTAUT framework, extending its relevance to individual consumers; this is termed UTAUT2. The UTAUT2 model was introduced in 2012 and is considered the latest structured model to explain the adoption of technology in the individual consumer context.

Considering that UTAUT integrates the various fragmented theories and researches into a unified theoretical model to explain the organizational adoption of technology and that the extended model UTAUT2 brings in the relevance of the model to individual consumers, UTAUT2 is widely used by researchers to explain the adoption of technology by individual consumers and organizations.

Online shopping fundamentally is nothing but the adoption of technology in conducting the age-old function of shopping. Therefore, technology acceptance theories are relevant in explaining the adoption of technology in the age old human activity of shopping as well.

Because of these reasons and theoretical background, the UTAUT2 framework is appropriate for conducting such research and is hence used as the base research framework in the current study. Table 1 contains the definition of the seven constructs of the UTAUT2 framework. 


\begin{tabular}{|l|l|}
\hline \multicolumn{2}{|c|}{ Table 1 - Definition of UTAUT2 Constructs } \\
\hline $\begin{array}{l}\text { 1. } \begin{array}{l}\text { Performance } \\
\text { Expectancy }\end{array} \\
\text { 2. } \begin{array}{l}\text { Effort } \\
\text { Expectancy }\end{array}\end{array}$ & $\begin{array}{l}\text { Degree to which using a technology will provide benefits to consumers in } \\
\text { performing certain activities (Venkatesh et al., 2012). } \\
\text { 2012). }\end{array}$ \\
\hline $\begin{array}{l}\text { 3. } \text { Social } \\
\text { Influence }\end{array}$ & $\begin{array}{l}\text { Extent to which consumers perceive that important others (e.g., family and } \\
\text { friends) believe they should use a particular technology (Venkatesh et al., 2012). }\end{array}$ \\
\hline $\begin{array}{l}\text { 4. } \\
\text { Facilitating } \\
\text { Conditions }\end{array}$ & $\begin{array}{l}\text { Consumers' perceptions of the resources and support available to perform a } \\
\text { behavior (Venkatesh et al., 2003; Brown \& Venkatesh, 2005). }\end{array}$ \\
\hline $\begin{array}{l}\text { 5. } \text { Hedonic } \\
\text { Motivation }\end{array}$ & Fun or pleasure derived from using a technology (Brown \& Venkatesh, 2005). \\
\hline 6. Price Value & $\begin{array}{l}\text { Consumers' cognitive tradeoff between the perceived benefits of the applications } \\
\text { and the monetary cost of using them (Dodds et al., 1991). }\end{array}$ \\
\hline 7. Habit & $\begin{array}{l}\text { Extent to which people tend to perform behaviors automatically because of } \\
\text { learning (Limayem et al., 2007). }\end{array}$ \\
\hline
\end{tabular}

\section{UTAUT2 Constructs and Hypotheses}

\section{Performance Expectancy (PE)}

Performance expectancy is the expectation that by using technology for some activity, the user's performance will improve. The five constructs from the different predecessor models that pertain to performance expectancy are perceived usefulness (TAM and C-TAM-TPB), extrinsic motivation (MM), job fit (MPCU), relative advantage (IDT), and outcome expectations (SCT) (Venkatesh et al., 2003). By conducting shopping online, users can expect to receive some benefits such as saving time, increased convenience, and so forth. Online shopping could be useful to users because they can conduct online shopping faster, see the products offered by different sellers, save time, and also conduct the shopping from the place of their convenience. These possible improvements in their performance could be the reasons behind the intention to use online shopping.

Regarding performance expectancy, the following are the proposed hypotheses:
H1_AT. Performance expectancy has a positive effect on the user's intention to use online shopping for an airline ticket purchase.

H1_B. Performance expectancy has a positive effect on the user's intention to use online shopping for a book purchase.

\section{Effort Expectancy (EE)}

Effort expectancy represents the ease of using technology. Constructs from the predecessor models that capture the concept of effort expectancy are perceived ease of use (TAM), complexity (MPCU), and ease of use (IDT) (Venkatesh et al., 2003). If a user thinks that it is easy to use the technology for conducting an activity, then the user may have a higher acceptance for the new technology. In this case, if the user thinks that using the Internet for shopping is easy, then this could facilitate the intention to use online shopping.

Regarding effort expectancy, the following are the proposed hypotheses: 
H2_AT: Effort expectancy has a positive effect on the user's intention to use online shopping for an airline ticket purchase.

H2_B: Effort expectancy has a positive effect on the user's intention to use online shopping for a book purchase.

\section{Social Influence (SI)}

Social influence represents the social pressure from important others, such as family, friends, and so forth for the adoption of new technology. Related constructs from the predecessor models, which are direct determinants of intention to use, are represented as subjective norm (TRA, TAM, TPB, C-TAM-TPB), social factors (MPCU), and image (IDT) (Venkatesh et al., 2003). If socially connected people are using newer web technologies for shopping, then this could be a factor of influence for intention to use. Social influence could be explicit or perceived. Regarding social influence, the following are the proposed hypotheses:

H3_AT: Social influence has a positive effect on the user's intention to use online shopping for an airline ticket purchase.

H3_B: Social influence has a positive effect on the user's intention to use online shopping for a book purchase.

\section{Facilitating Conditions (FC)}

Facilitating conditions represents the required items and support needed to use new technology. Related constructs from the predecessor models, which are direct determinants of intention to use and actual use, are represented as perceived behavioral control (TPB, C-TAM-TPB), facilitating conditions (MPCU), and compatibility (IDT) (Venkatesh et al., 2003). For online shopping, facilitating conditions could include computers, smartphones, Internet, online customer support, required knowledge, skills, and so forth. Facilitating conditions can influence both intention to use and use behavior. Regarding facilitating conditions, the following are the proposed hypotheses:
H4_AT: Facilitating conditions have a positive effect on the user's intention to use online shopping for an airline ticket purchase.

H5_AT: Facilitating conditions have a positive effect on the user's online shopping use for an airline ticket purchase.

H4_B: Facilitating conditions have a positive effect on the user's intention to use online shopping for a book purchase.

H5_B: Facilitating conditions have a positive effect on the user's online shopping use for a book purchase.

\section{Hedonic Motivation (HM)}

Hedonic motivation is defined as the fun or pleasure derived from using a technology, and it has been shown to play an important role in determining technology acceptance and use (Brown \& Venkatesh, 2005). In information systems research, hedonic motivation (conceptualized as perceived enjoyment) has been found to influence technology acceptance and use directly (Van der Heijden, 2004; Thong et al., 2006). In the consumer context, hedonic motivation has also been found to be an important determinant of technology acceptance and use (Brown \& Venkatesh, 2005; Childers et al., 2001). For some users, using something new and innovative itself could be exciting and entertaining; hence, hedonic motivation can have an influence on intention to use. Regarding hedonic motivation, the following are the proposed hypotheses:

H6_AT: Hedonic motivation has a positive effect on the user's intention to use online shopping for an airline ticket purchase.

H6_B: Hedonic motivation has a positive effect on the user's intention to use online shopping for a book purchase.

\section{Price Value (PV)}

Price value is defined as consumers' cognitive tradeoff between the perceived benefits of the applications and the monetary cost for using them (Dodds et al., 1991). The price value is positive when the 
benefits of using a technology are perceived to be greater than the monetary cost, and such price value has a positive impact on intention (Venkatesh et al., 2012). Online shopping can offer lower prices to consumers because of the lower operating cost structure of online businesses. The monetary benefit from online shopping could be derived from the lower prices and also through the possible savings from easy price comparisons, online discount offers, lower transportation costs in procuring a product, and so forth. Regarding price value, the following are the proposed hypotheses:

H7_AT: Price value has a positive effect on the user's intention to use online shopping for an airline ticket purchase.

H7_B: Price value has a positive effect on the user's intention to use online shopping for a book purchase.

\section{Habit (HT)}

Habit is defined as the extent to which people tend to perform behaviors automatically because of learning (Limayem et al., 2007). The passage of chronological time (i.e., experience) can result in the formation of differing levels of habit, depending on the extent of interaction and familiarity that is developed with a target technology. The empirical findings about the role of habit in technology use have delineated different underlying processes by which habit influences technology use (Venkatesh et al., 2012). Habit represents the involuntary behavior to use technology for any activity. Habitual users of online shopping will tend to browse online stores as part of their natural behavior. Habit can have influence on both intention to use and use behavior. Regarding habit, the following are the proposed hypotheses:

H8_AT: The habit of online shopping has a positive effect on the user's intention to use online shopping for an airline ticket purchase.

H9_AT: The habit of online shopping has a positive effect on the user's online shopping use for an airline ticket purchase.
H8_B: The habit of online shopping has a positive effect on the user's intention to use online shopping for a book purchase.

H9_B: The habit of online shopping has a positive effect on the user's online shopping use for a book purchase.

\section{Additional Constructs to UTAUT2}

\section{Long Tail Effect (LT)}

Businesses are creating innumerable new products every day because of the changing needs of consumers, product innovations, and so forth. However, traditional brick-andmortar businesses have limited space to keep the inventory in their retail stores. Generally, these stores limit the stock in their stores to the best-selling products only. On the other hand, online stores have no such constraints to limit the number of products. They can even display products that have very low demand. This results in an inclusion of a long list of product offerings that individually have a low demand but collectively forms a significant amount of sales. This phenomenon is called the "long tail effect." Information technology in general and internet markets in particular have the potential to substantially increase the collective share of niche products, thereby creating a longer tail in the distribution of sales (Brynjolfsson et al., 2011).

There are many past studies emphasizing LT as the strength of e-commerce, but there is hardly any research examining the importance of large product selection or product variety as a reason for the user to adopt online shopping. Even UTAUT2 does not contain a variety of product offerings as a factor for customer motivation behind online shopping use. In the current research, $\mathrm{LT}$ is proposed as an additional construct to analyze the user motivations behind online shopping. Regarding LT, the following are the proposed hypotheses:

H12_AT: A large product selection available at an online store, results in a positive effect 
on the user's intention to use online shopping for an airline ticket purchase.

H12_B: A large product selection available at an online store, results in a positive effect on the user's intention to use online shopping for a book purchase.

\section{Trust (TR)}

Trust is important in any buy-sell transaction, but it becomes crucial when the transaction is conducted through the Internet. As online shopping involves transactions through Internet, all the inherent risks associated with the use of the Internet such as online fraud, data privacy, security issues, and so forth become relevant. Besides these issues, a lack of face-to-face interactions with the seller accentuates the sense of insecurity and anxiety in the user. In such a situation, whether an online vendor is trustworthy, and whether the online vendor has taken sufficient actions to safeguard the interests of users becomes an important pre-requisite for the use of online shopping.

Many prior studies emphasize the importance of users' trust in the adoption of online shopping. Trust is crucial in many transactional, buyer-seller relationships, especially those containing an element of risk, including ones where there are interactions with an e-vendor (Reichheld \& Schefter, 2000). Consumer trust is as important to online commerce as the widely accepted TAM use-antecedents, perceived usefulness, and perceived ease of use (Gefen et al., 2003).

Trust has various aspects in the ecommerce context, such as whether online shops will keep their promises and commitments regarding their products and services, whether they will ensure the security of the transactions, and whether they will consistently stay trustworthy through their capabilities. Trust can influence both intention to use and use behavior. Regarding trust, the following are the proposed hypotheses:
H10_AT: Trust in an online vendor has a positive effect on the user's intention to use online shopping for an airline ticket purchase.

H11_AT: Trust in an online vendor has a positive effect on the user's online shopping use for an airline ticket purchase.

H10_B: Trust in an online vendor has a positive effect on the user's intention to use online shopping for a book purchase.

H11_B: Trust in an online vendor has a positive effect on the user's online shopping use for a book purchase.

\section{Intention to Use (IU) and Use Behavior (UB)}

Besides the seven constructs of the UTAUT2 framework, LT, and trust, the following hypotheses are proposed as being related to intention to use and use behavior:

H13 AT: The user's intention to use online shopping has a positive effect on the online shopping use for an airline ticket purchase.

H13 B: The user's intention to use online shopping has a positive effect on the online shopping use for a book purchase.

\section{Research Methodology}

\section{Measurements}

This research was conducted in Japan to understand the user motivations behind online shopping using UTAUT2 framework, in addition to two newly proposed constructs LT and trust. For this purpose, user data was collected related to online shopping for two products: an airline ticket and book. The measurement items related to the seven constructs in UTAUT2 and trust were adopted from various related studies (Venkatesh et al., 2012; Escobar-Rodriguez \& Carvajal-Trujillo, 2013; Hong \& Cha, 2013; Gefen et al., 2003). However, because there is no prior study on understanding the effect of LT on customer motivation behind online shopping, new measurement items 
were created for the LT construct. Corresponding to the total nine constructs and intention to use, 35 measurement items were created for airline ticket and 35 for book. Use behavior was measured by asking the average number of times in a year, an airline ticket or book was purchased through online channels. Measurement items for both the products are included at the end of this research paper. Besides these, a few other measurement items related to user demographics were created.

All the measurement items were first compiled in a questionnaire in English, and then, the Japanese version of the questionnaire was created. Native Japanese academic professionals reviewed the first round of the Japanese version of the questionnaire, which was further reviewed by 10 other native Japanese professionals, and their feedback was incorporated into the questionnaire. Finally, the Japanese version was independently translated back into English to ensure consistency between the English and Japanese versions of the questionnaires. The questionnaire was based on a 5-point Likert scale that ranged from 1 (Strongly Disagree) to 5 (Strongly Agree).

\section{Participants and Data Collection}

Initially, the questionnaire was conducted independently, face to face with 10 native Japanese respondents to ensure that the questions were clear and easy to understand. The survey was administered online as well as through a paper-based questionnaire. For the online data collection, the web-based survey software Survey Monkey was used, and the questions in the questionnaire were set in random mode so that each respondent would receive a random sequence of questions. The first level of respondents were students, staff, and faculty members of three universities in Japan, employees of two companies in Japan, and social contacts on social networking websites such as Facebook.

The first level of respondents were encouraged to forward the online questionnaire link to their family members and friends. A total of 630 people were directly approached for the questionnaire. First level respondents were 392 and 87 were through the referrals of the first level of respondents. The response rate of first level of respondents was $62 \%$. Out of total 479 respondents, around $82 \%$ of the respondents were the first level of respondents, and around $18 \%$ came through referrals.

The survey was conducted over a 5-month period from December 2015 to April 2016. Out of the total 479 respondents, 16 had no experience with online shopping, and 20 had never purchased an airline ticket or book through online shopping. These 36 respondents were excluded from the data, resulting in a total of 443 respondents who had experience in online shopping for an airline ticket, book, or both.

Out of the 443 respondents, 91 had experience only with books, so the total population for an airline ticket became 352, while 66 had experience only with an airline ticket but not with a book, so the total population for books became 377. As a general rule, the minimum sample size should be at least five times as many observations as the number of variables to be analyzed, and a more acceptable sample size would be to have a 10:1 ratio (Hair et al., 2009). A sample size of 352 is more than a 10:1 ratio.

Below are the respondent demographics of the sample population. 


\begin{tabular}{|c|c|c|}
\hline & Airline Ticket & Book \\
\hline Airline Ticket Only & 66 & 0 \\
\hline Book Only & 0 & 91 \\
\hline Airline Ticket \& Book both & 286 & 286 \\
\hline TOTAL & 352 & 377 \\
\hline No Airline Ticket \& Book & 20 & 20 \\
\hline No Online Shopping experience & 16 & 16 \\
\hline TOTAL Responses & $\begin{array}{c}\mathbf{4 7 9} \\
(352+91+20+16)\end{array}$ & $\begin{array}{c}\mathbf{4 7 9} \\
(377+66+20+16)\end{array}$ \\
\hline
\end{tabular}

\section{Table 3 - Respondent Demographics (Airline Ticket and Book)}

\begin{tabular}{|c|c|c|c|c|c|}
\hline & & & & & \\
\hline \multirow{3}{*}{ Gender } & Male & 161 & $54 \%$ & 166 & $44 \%$ \\
\hline & Female & 191 & $46 \%$ & 211 & $56 \%$ \\
\hline & Total & 352 & $100 \%$ & 377 & $100 \%$ \\
\hline \multirow{7}{*}{ Age } & $15-19$ years & 26 & $7 \%$ & 26 & $7 \%$ \\
\hline & $20-24$ years & 102 & $29 \%$ & 121 & $32 \%$ \\
\hline & $25-29$ years & 68 & $19 \%$ & 76 & $20 \%$ \\
\hline & $30-34$ years & 50 & $14 \%$ & 52 & $14 \%$ \\
\hline & $35-39$ years & 48 & $14 \%$ & 48 & $13 \%$ \\
\hline & Above 40 years & 58 & $17 \%$ & 54 & $14 \%$ \\
\hline & Total & 352 & $100 \%$ & 377 & $100 \%$ \\
\hline \multirow{7}{*}{ Occupation } & Full-time employee & 111 & $31 \%$ & 120 & $32 \%$ \\
\hline & Part-time/contract employee & 69 & $20 \%$ & 62 & $16 \%$ \\
\hline & Self-employed & 17 & $5 \%$ & 17 & $5 \%$ \\
\hline & Housewife & 28 & $8 \%$ & 28 & $7 \%$ \\
\hline & Unemployed & 9 & $3 \%$ & 10 & $3 \%$ \\
\hline & Student & 118 & $33 \%$ & 140 & $37 \%$ \\
\hline & Total & 352 & $100 \%$ & 377 & $100 \%$ \\
\hline
\end{tabular}

\section{Analyses and Results}

For the analysis, structural equation modeling (SEM) was conducted using SPSS 23 and AMOS 23. SEM simultaneously tests multiple hypotheses by estimating the relationships between a set of multiple independent and dependent variables in a structural model (Gefen et al., 2000). SEM can impute relationships between unobserved constructs from observed variables, which was required in the current study and hence was selected for the analysis. The constructs in the current research are reflective and not formative. The causal action flows from the latent variables such as performance expectancy, effort expectancy, and so forth to the respective measurement items.

\section{Measurement Model}

Based on the total of nine constructs and intention to use, a measurement model was created. A factor analysis was conducted to examine the convergent validity, discriminant validity, and reliability of the constructs. A factor analysis is an interdependence technique whose primary purpose is to determine the underlying structure among the variables in the analysis (Hair et al., 2009). 
Multicollinearity means that the variance independent variables explain in dependent variables are overlapping each other and thus are not explaining unique variance in the dependent variable. The simplest and most obvious means of identifying collinearity is an examination of the correlation matrix for the independent variables. The presence of high correlations (generally 0.9 and higher) is the first indication of substantial collinearity. Also, multicollinearity can be tested by a variance inflation factor (VIF) for which the suggested threshold is 3 with an acceptable threshold of 5 (Hair et al., 2009). As shown in Table 5 and Table 7, none of the correlations between the independent variables was found to be more than 0.7 , and also no VIF for any of the variables was found to be higher than 3 for both product categories. The VIF was found to be ranging between 1.2 and 2.1. Therefore, no significant multicollinearity problem exists in the data.

Common method bias is attributable to the measurement method rather than to the constructs the measures present (Podsakoff et al., 2003). The common method bias could be because of external reasons such as data collection or factors that may bring in the bias that may either inflate or deflate responses. For the current study, common method bias was tested using the common latent factor method, which was done by capturing the common variance among all the observed variables in the model using AMOS software. For the model, standardized regression weights were compared with an additional common latent factor and without a common latent factor. The difference between the two sets of standardized regression weights were not found to be significantly high. In addition to this, Harman's single factor test was also conducted, and none of the single factors explained the variance more than $50 \%$, hence passing Harman's one factor test. Both the tests indicated the absence of any considerable common method bias in the data.
The convergent validity of the scales should be assessed using two criteria (Fornell \& Larcker, 1981): (1) all indicator loadings should be significant and exceed 0.7 , and (2) the average variance extracted (AVE) by each construct should exceed the variance caused by the measurement error for that construct (i.e., AVE should exceed 0.5). Factor loadings in the range of \pm 0.30 to \pm 0.40 are considered to meet the minimal level for interpretation of structure and loadings, and \pm 0.50 or greater are considered practically significant (Hair et al., 2009). For convergent validity, a pattern matrix was examined to check the factor loadings of the measurement items on the respective constructs and the cross-factor loadings. A factor analysis was conducted using the maximum likelihood estimation method and promax rotation. For the current study, all the factor loadings were greater than 0.7 except for one item in facilitating conditions, price value, habit, and intention to use for airline ticket. Similarly, all the factor loadings were greater than 0.7 for book except for one item in facilitating condition and LT. None of the items had a factor loading of less than 0.6 and crossloading higher than 0.2 . In addition to this, for all the constructs, AVE exceeded 0.5, hence passing the convergent validity test.

For airline ticket data analysis, two measurement items were excluded from the analysis because of their low factor loading and high cross-loadings. One measurement item was related to the habit construct and the other to facilitating conditions. For books data analysis, one measurement item related to facilitating conditions was excluded.

Validity is how well the concept is defined by the measures, whereas reliability relates to the consistency of the measures (Hair et al., 2009). Reliability was tested through the computation of Cronbach's alpha for each factor. The generally agreed upon lower limit for Cronbach's alpha is 0.70 although it may decrease to 0.60 in exploratory research (MacCallum et al., 1994). Cronbach's alpha for each construct was 
found to be higher than 0.7 , as shown in the results below, hence passing the reliability criteria.
Below are the results for the reliability test and convergent validity test for airline tickets and books.

\begin{tabular}{|c|c|c|c|c|c|c|}
\hline & \multicolumn{3}{|c|}{ Airline Ticket (AT) } & \multicolumn{3}{|c|}{ Book (B) } \\
\hline Construct & Scale Item & $\begin{array}{c}\text { Cronbach`s } \\
\text { Alpha }\end{array}$ & $\begin{array}{l}\text { Factor } \\
\text { Loading }\end{array}$ & Scale Item & $\begin{array}{c}\text { Cronbach`s } \\
\text { Alpha }\end{array}$ & $\begin{array}{c}\text { Factor } \\
\text { Loading }\end{array}$ \\
\hline \multirow{4}{*}{$\begin{array}{l}\text { Performance } \\
\text { Expectancy }\end{array}$} & PE1_AT & \multirow{4}{*}{0.898} & 0.728 & PE1_B & \multirow{4}{*}{0.921} & 0.780 \\
\hline & PE2_AT & & 0.926 & PE2_B & & 0.923 \\
\hline & PE3_AT & & 0.776 & PE3_B & & 0.836 \\
\hline & PE4_AT & & 0.876 & PE4_B & & 0.887 \\
\hline \multirow{4}{*}{$\begin{array}{c}\text { Effort } \\
\text { Expectancy }\end{array}$} & EE1_AT & \multirow{4}{*}{0.895} & 0.831 & EE1_B & \multirow{4}{*}{0.921} & 0.893 \\
\hline & EE2_AT & & 0.821 & EE2_B & & 0.805 \\
\hline & EE3_AT & & 0.856 & EE3_B & & 0.869 \\
\hline & EE4_AT & & 0.805 & EE4_B & & 0.844 \\
\hline \multirow{3}{*}{$\begin{array}{c}\text { Social } \\
\text { Influence }\end{array}$} & SI1_AT & \multirow{3}{*}{0.929} & 0.898 & SI1_B & \multirow{3}{*}{0.935} & 0.913 \\
\hline & SI2_AT & & 0.848 & SI2_B & & 0.898 \\
\hline & SI3_AT & & 0.938 & SI3_B & & 0.901 \\
\hline \multirow{4}{*}{$\begin{array}{l}\text { Facilitating } \\
\text { Conditions }\end{array}$} & FC1_AT & \multirow{4}{*}{0.824} & 0.850 & FC1_B & \multirow{4}{*}{0.816} & 0.822 \\
\hline & FC2_AT & & 0.796 & FC2_B & & 0.797 \\
\hline & FC3_AT & & 0.631 & FC3_B & & 0.678 \\
\hline & FC4_AT & & Dropped & FC4_B & & Dropped \\
\hline \multirow{3}{*}{$\begin{array}{l}\text { Hedonic } \\
\text { Motivation }\end{array}$} & HM1_AT & \multirow{3}{*}{0.934} & 0.918 & HM1_B & \multirow{3}{*}{0.934} & 0.927 \\
\hline & HM2_AT & & 0.901 & HM2_B & & 0.927 \\
\hline & HM3_AT & & 0.824 & HM3_B & & 0.877 \\
\hline \multirow{3}{*}{ Price Value } & PV1_AT & \multirow{3}{*}{0.826} & 0.794 & PV1_B & \multirow{3}{*}{0.88} & 0.786 \\
\hline & PV2_AT & & 0.683 & PV2_B & & 0.888 \\
\hline & PV3_AT & & 0.793 & PV3_B & & 0.787 \\
\hline \multirow{4}{*}{ Habit } & HT1_AT & \multirow{4}{*}{0.839} & 0.861 & HT1_B & \multirow{4}{*}{0.919} & 0.866 \\
\hline & HT2_AT & & 0.876 & HT2_B & & 0.884 \\
\hline & HT3_AT & & Dropped & HT3_B & & 0.838 \\
\hline & HT4_AT & & 0.615 & HT4_B & & 0.793 \\
\hline \multirow{4}{*}{ Trust } & TR1_AT & \multirow{4}{*}{0.916} & 0.858 & TR1_B & \multirow{4}{*}{0.947} & 0.903 \\
\hline & TR2_AT & & 0.827 & TR2_B & & 0.909 \\
\hline & TR3_AT & & 0.797 & TR3_B & & 0.837 \\
\hline & TR4_AT & & 0.88 & TR4_B & & 0.888 \\
\hline \multirow{3}{*}{$\begin{array}{l}\text { Long Tail } \\
\text { Effect }\end{array}$} & LT1_AT & & 0.883 & LT1_B & & 0.936 \\
\hline & LT2_AT & 0.884 & 0.934 & LT2_B & 0.908 & 0.926 \\
\hline & LT3_AT & & 0.742 & LT3_B & & 0.692 \\
\hline & IU1_AT & & 0.875 & IU1_B & & 0.831 \\
\hline $\begin{array}{l}\text { Intention to } \\
\text { Use }\end{array}$ & IU2_AT & 0.906 & 0.648 & IU2_B & 0.961 & 0.868 \\
\hline & IU3_AT & & 0.819 & IU3_B & & 0.811 \\
\hline
\end{tabular}


Discriminant validity shows to what extent factors are distinct and uncorrelated. Discriminant validity should be assessed via the following criterion: the square root of the AVE of a construct should be greater than the correlations between the construct and all other constructs in the model (Fornell \& Larcker, 1981).

As shown in Tables 5 and 6 for airline tickets and in Tables 7 and 8 for books, the square root of the AVE was found to be greater than the correlations between the constructs in the model, hence passing the discriminant validity test. Also, none of the correlations between the factors exceeded 0.7 , which is also an indicator of passing the discriminant validity test.

Below, Table 5 contains the factor correlation matrix, and Table 6 contains the square root of AVE for airline tickets.

Table 7 contains the factor correlation matrix, and Table 8 contains the square root of AVE for the book.

\begin{tabular}{|c|c|c|c|c|c|c|c|c|c|c|}
\hline Factor & PE & EE & SI & FC & HM & PV & HT & TR & LT & IU \\
\hline PE & 1.0 & & & & & & & & & \\
\hline EE & .49 & 1.0 & & & & & & & & \\
\hline SI & .23 & .28 & 1.0 & & & & & & & \\
\hline FC & .45 & .55 & .24 & 1.0 & & & & & & \\
\hline HM & .34 & .49 & .21 & .36 & 1.0 & & & & & \\
\hline PV & .46 & .49 & .19 & .52 & .57 & 1.0 & & & & \\
\hline HT & .41 & .39 & .36 & .39 & .44 & .48 & 1.0 & & & \\
\hline TR & .45 & .44 & .14 & .44 & .48 & .54 & .47 & 1.0 & & \\
\hline LT & .18 & .23 & .32 & .20 & .18 & .24 & .16 & .04 & 1.0 & \\
\hline IU & .59 & .54 & .33 & .55 & .50 & .69 & .65 & .58 & .29 & 1.0 \\
\hline
\end{tabular}

\section{Table 6 - AVE and Square root of AVE (Airline Ticket)}

\begin{tabular}{|l|c|c|}
\hline \multicolumn{1}{|c|}{ Factor } & AVE & Square Root of AVE \\
\hline Performance Expectancy & 0.689 & 0.830 \\
\hline Effort Expectancy & 0.686 & 0.828 \\
\hline Social Influence & 0.801 & 0.895 \\
\hline Facilitating Conditions & 0.584 & 0.764 \\
\hline Hedonic Motivation & 0.777 & 0.881 \\
\hline Price Value & 0.575 & 0.758 \\
\hline Habit & 0.628 & 0.793 \\
\hline Trust & 0.707 & 0.841 \\
\hline Long Tail Effect & 0.734 & 0.856 \\
\hline
\end{tabular}




\begin{tabular}{|c|c|c|c|c|c|c|c|c|c|c|}
\hline Factor & PE & EE & SI & FC & HM & PV & HT & TR & LT & IU \\
\hline PE & 1.0 & & & & & & & & & \\
\hline EE & .53 & 1.0 & & & & & & & & \\
\hline SI & .35 & .33 & 1.0 & & & & & & & \\
\hline FC & .54 & .54 & .19 & 1.0 & & & & & & \\
\hline HM & .35 & .35 & .27 & .33 & 1.0 & & & & & \\
\hline PV & .50 & .44 & .34 & .42 & .24 & 1.0 & & & & \\
\hline HT & .37 & .35 & .36 & .35 & .27 & .47 & 1.0 & & & \\
\hline TR & .58 & .58 & .35 & .54 & .32 & .54 & .47 & 1.0 & & \\
\hline LT & .59 & .48 & .27 & .46 & .29 & .55 & .36 & .59 & 1.0 & \\
\hline IU & .68 & .57 & .39 & .54 & .37 & .62 & .64 & .70 & .65 & 1.0 \\
\hline
\end{tabular}

\section{Table 8 - AVE and Square root of AVE (Book)}

\begin{tabular}{|l|c|c|}
\multicolumn{1}{|c|}{ Factor } & AVE & Square Root of AVE \\
\hline Performance Expectancy & 0.736 & 0.858 \\
\hline Effort Expectancy & 0.728 & 0.853 \\
\hline Social Influence & 0.817 & 0.904 \\
\hline Facilitating Conditions & 0.590 & 0.768 \\
\hline Hedonic Motivation & 0.829 & 0.910 \\
\hline Price Value & 0.675 & 0.821 \\
\hline Habit & 0.715 & 0.845 \\
\hline Trust & 0.782 & 0.880 \\
\hline Long Tail Effect & 0.737 & 0.858 \\
\hline
\end{tabular}

\section{Structural Model}

Structural equation modeling was conducted for the selected product categories with seven constructs of UTAUT2, LT, trust, intention to use, and use behavior. Model fit indices were analyzed to ensure that the model could be used.

The chi-square value is the traditional measure used for evaluating overall model fit, and it assesses the magnitude of discrepancy between the sample and fitted covariance matrices (Hu \& Bentler, 1999). A good model fit provides an insignificant result at the 0.05 threshold (Barrett, 2007).

The RMSEA value between 0.08 and 0.10 provides a mediocre fit, and anything below 0.08 shows a good fit (MacCallum et al.,
1996). However, more recently, a stringent upper limit of 0.07 (Steiger, 2007) seems to be the general consensus among the authorities in this area.

A cut-off criterion of $\mathrm{CFI} \geq 0.90$ was initially considered to be high; however, recent studies have shown that a value greater than 0.90 is needed to ensure that misspecified models are not accepted ( $\mathrm{Hu}$ \& Bentler, 1999). Values for the standardized RMR range from zero to 1.0, with well-fitting models obtaining values less than .05 (Byrne, 1998; Diamantopoulos \& Signaw, 2000); however, values as high as 0.08 are deemed acceptable (Hu \& Bentler, 1999).

The path diagram of the testing model for airline tickets and books are shown below. 
Pacific Asia Journal of the Association for Information Systems, Vol. 9, Iss. 4 [2018], Art. 2

How Long Tail and Trust Affect Online Shopping Behavior / Singh and Matsui

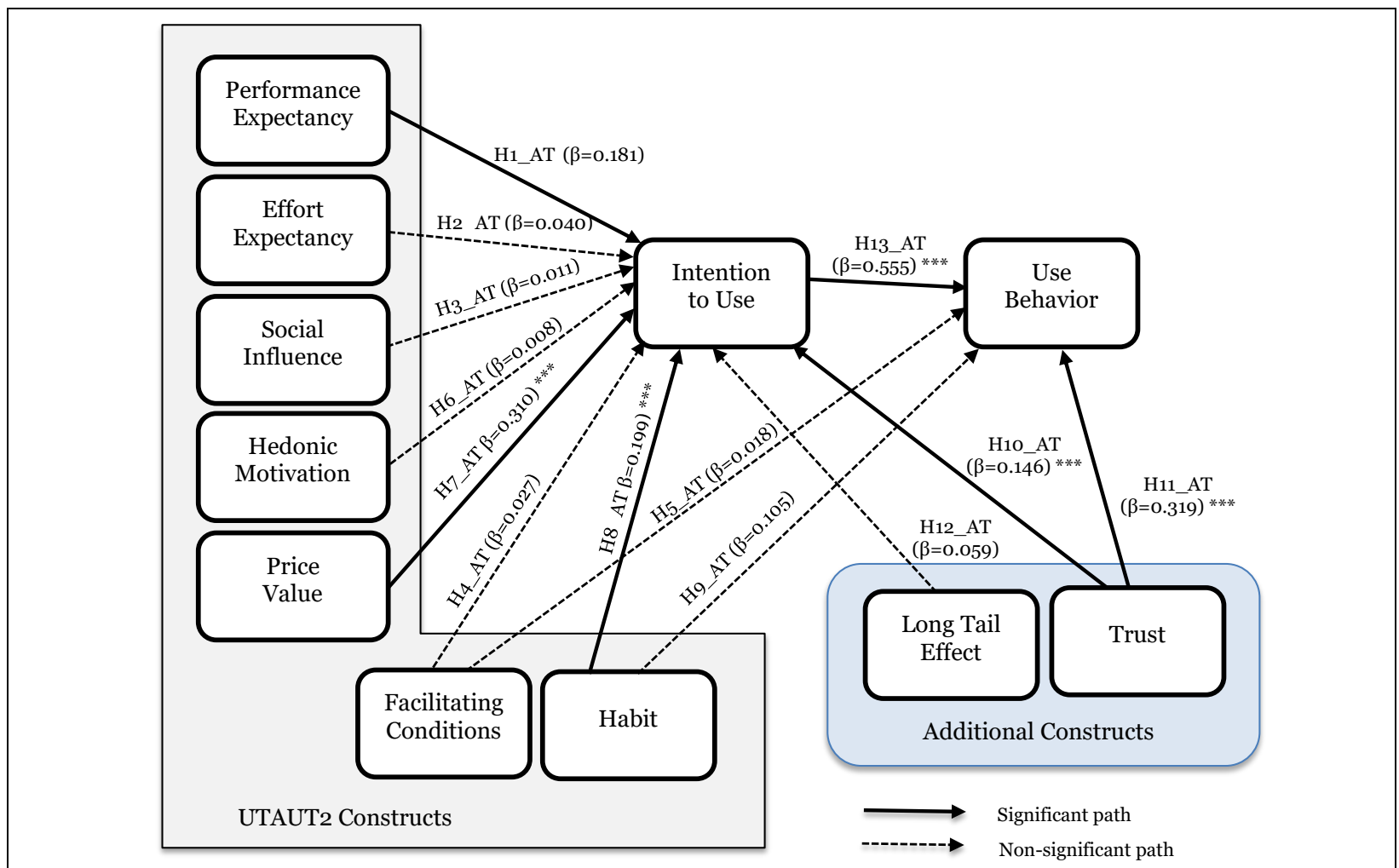

\section{Figure 1 - Results of the Testing Model (Airline Ticket)}

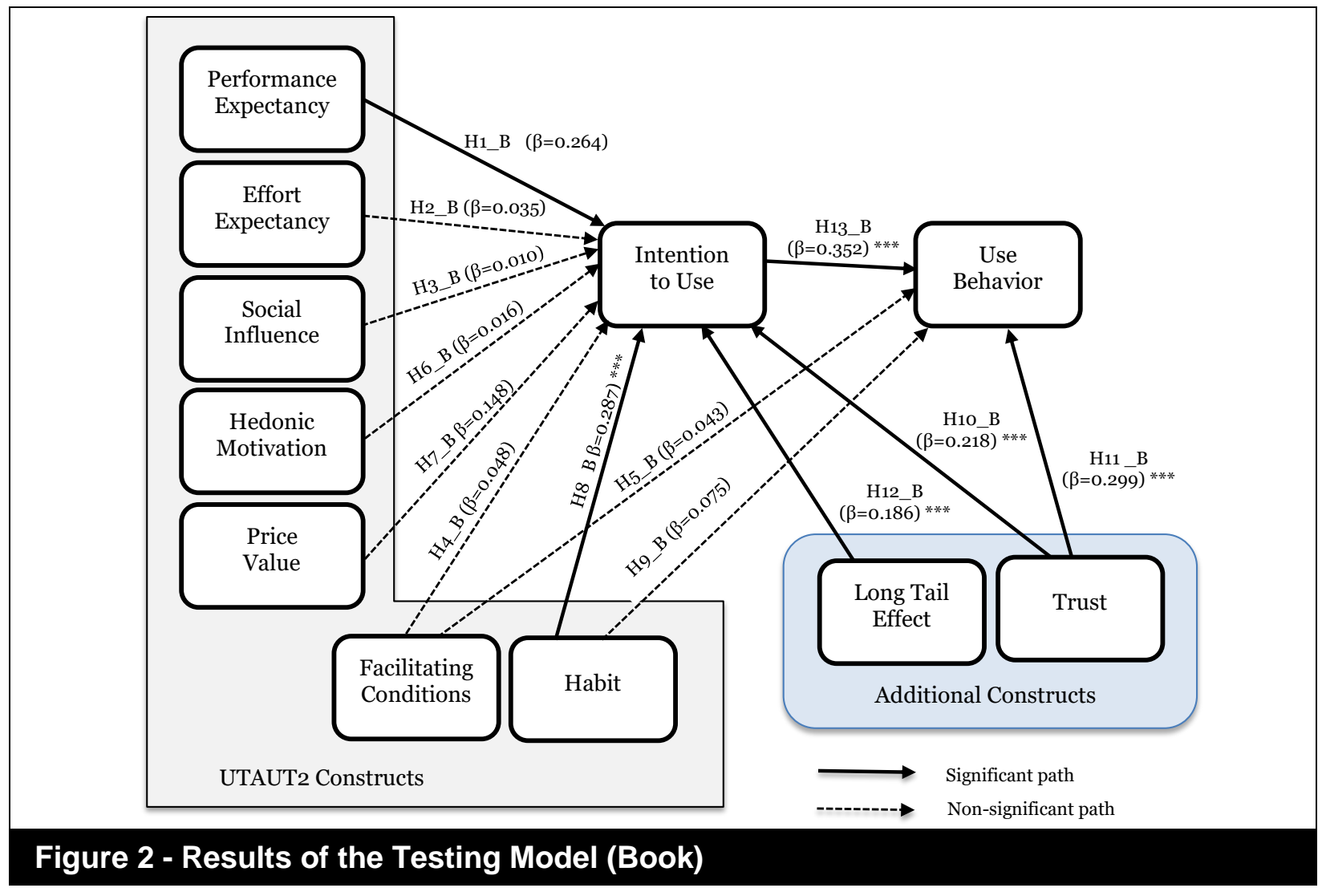

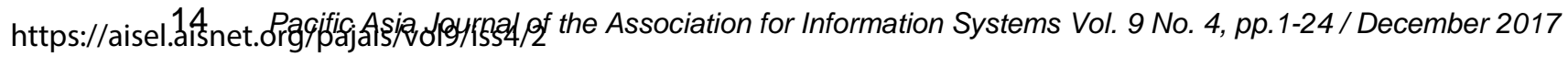


For airline tickets, the chi-square was 1111.8 with 479 degrees of freedom. The root mean square error of approximation (RMSEA) was 0.061 , comparative fit index (CFI) was 0.930 , and root mean square residual (RMR) was 0.035 . All these model fit indices indicated the acceptance of the model for airline tickets.

For books, the chi-square was 1068.9 with 512 degrees of freedom. The RMSEA was 0.054 , CFI was 0.955, and RMR was 0.039. All these model fit indices indicated the acceptance of the model for books.

\section{Results}

For airline tickets, all the seven constructs of UTAUT2 along with the additional constructs trust and LT had positive regression weights; however, only price value, habit, performance expectancy, and trust were found to have a significant positive effect on intention to use. It is important to note that among the additionally proposed two constructs of LT and trust, only trust was found to have a significant relationship with intention to use while LT was not found to have a significant relation with intention to use.

Similarly, facilitating conditions, habit, and trust had positive regression weights, but only trust was found to have a significant positive direct effect on use behavior. Also, it was found that intention to use has a significant positive effect on use behavior. A summary of the test results for airline tickets is shown below.

\section{Table 9 - Summary of Test Results for the Structural Model (Airline Ticket)}

\begin{tabular}{|c|c|c|c|c|c|c|}
\hline & Hypothesis & Path & $\begin{array}{c}\text { Regression } \\
\text { Weight }\end{array}$ & $\begin{array}{c}\text { Critical } \\
\text { Ratio }(z)\end{array}$ & Significance & Supported \\
\hline \multirow{9}{*}{$\begin{array}{c}\text { Intention to } \\
\text { Use }\end{array}$} & H1_AT & $P E-I U$ & 0.181 & 4.052 & $* * *$ & Yes \\
\hline & H2_AT & $E E-I U$ & 0.040 & 0.916 & 0.360 & No \\
\hline & H3_AT & $S I-I U$ & 0.011 & 0.452 & 0.651 & No \\
\hline & H4_AT & $F C-I U$ & 0.027 & 0.527 & 0.598 & No \\
\hline & H6_AT & $\mathrm{HM}-\mathrm{IU}$ & 0.008 & 0.259 & 0.796 & No \\
\hline & H7_AT & $P V-I U$ & 0.310 & 4.918 & $* \star * *$ & Yes \\
\hline & H8_AT & $\mathrm{HT}-\mathrm{IU}$ & 0.199 & 5.924 & $* * \star$ & Yes \\
\hline & H10_AT & $T R-I U$ & 0.146 & 3.657 & $* * *$ & Yes \\
\hline & H12_AT & $L T-I U$ & 0.059 & 2.170 & 0.030 & No \\
\hline \multirow{4}{*}{$\begin{array}{c}\text { Use } \\
\text { Behavior }\end{array}$} & H5_AT & $\mathrm{FC}-\mathrm{UB}$ & 0.018 & 0.174 & 0.862 & No \\
\hline & H9_AT & $\mathrm{HT}-\mathrm{UB}$ & 0.105 & 1.303 & 0.192 & No \\
\hline & H11_AT & $\mathrm{TR}-\mathrm{UB}$ & 0.319 & 3.499 & $* \star *$ & Yes \\
\hline & H13_AT & $I U-U B$ & 0.555 & 3.566 & $* * *$ & Yes \\
\hline
\end{tabular}

For books, all the seven constructs of UTAUT2 along with the additional constructs trust and $\mathrm{LT}$ had a positive regression weight; however, only habit, performance expectancy, trust, and LT were found to have a significant positive effect on intention to use. For this product, both the newly proposed constructs trust and LT were found to have a significant relationship with intention to use.
Similarly, facilitating conditions, habit, and trust had a positive regression weight, but only trust was found to have a significant positive direct effect on use behavior. Also, it was found that intention to use has a significant positive effect on use behavior. A summary of the test results for books is shown below. 


\begin{tabular}{|c|c|c|c|c|c|c|}
\hline & Hypothesis & Path & $\begin{array}{c}\text { Regression } \\
\text { Weight }\end{array}$ & $\begin{array}{r}\text { Critical } \\
\text { Ratio }(z)\end{array}$ & Significance & Supported \\
\hline \multirow{9}{*}{$\begin{array}{c}\text { Intention to } \\
\text { Use }\end{array}$} & H1_B & $P E-I U$ & 0.264 & 5.320 & $\star \star \star *$ & Yes \\
\hline & $\mathrm{H} 2 \_\mathrm{B}$ & $E E-I U$ & 0.035 & 0.799 & 0.424 & No \\
\hline & H3_B & $S I-I U$ & 0.010 & 0.335 & 0.738 & No \\
\hline & H4_B & $F C-I U$ & 0.048 & 0.813 & 0.416 & No \\
\hline & H6_B & $\mathrm{HM}-\mathrm{IU}$ & 0.016 & 0.579 & 0.562 & No \\
\hline & H7_B & $P V-I U$ & 0.148 & 2.829 & 0.005 & No \\
\hline & H8_B & $\mathrm{HT}-\mathrm{IU}$ & 0.287 & 9.390 & $* \star \star$ & Yes \\
\hline & H10_B & TR - IU & 0.218 & 4.759 & $\star \star \star *$ & Yes \\
\hline & H12_B & $L T-I U$ & 0.186 & 4.129 & $* * *$ & Yes \\
\hline \multirow{4}{*}{$\begin{array}{c}\text { Use } \\
\text { Behavior }\end{array}$} & H5_B & $F C-U B$ & 0.043 & 0.672 & 0.502 & No \\
\hline & H9_B & $\mathrm{HT}-\mathrm{UB}$ & 0.075 & 1.877 & 0.061 & No \\
\hline & H11_B & $T R-U B$ & 0.299 & 5.531 & $* * *$ & Yes \\
\hline & H13_B & $I U-U B$ & 0.352 & 5.437 & $* * *$ & Yes \\
\hline
\end{tabular}

\section{Conclusion}

The current research contributes to the understanding of user motivations behind online airline ticket and book purchases in Japan. The findings from this research indicate that user motivations behind intention to use for airline tickets are price value, habit, performance expectancy, and trust. However, direct predictors for use behavior were found to be intention to use and trust. Effort expectancy, social influence, facilitating conditions, hedonic motivation, and $L T$ have positive regression weights but were not significant predictors for intention to use.

User motivations behind intention to use for books were found to be habit, performance expectancy, trust, and LT. Direct predictors of use behavior were found to be intention to use and trust. Effort expectancy, social influence, facilitating conditions, hedonic motivation, and price value have positive regression weights but were not the significant predictors for intention to use.

Effort expectancy and facilitating conditions were not found to be significant predictors of intention to use. Effort expectancy reflects ease of use, and facilitating conditions reflects the items and support required to conduct online shopping. In a developed country such as Japan, where computers and laptops are basic commodities and the Internet penetration rate is among the highest in the world $(91 \%$ in 2015 ; Internet World Stats), facilitating conditions for online shopping and ease of use have become the norm. These factors may be positively affecting the adoption of online shopping, but just because one possesses the required items for online shopping and is adept at using them, will not necessarily result in intention to use or an actual purchase. This is also reflected in the findings of this research.

The effect of social influence was found to be insignificant, probably because users are already using online channels for general use of collecting information about tourism, places to visit, and so forth, but intention to use is not necessarily driven by social influence. Moreover, the number of habitual users and frequent users of online channels are increasing, and these users will tend to have a minimal effect from social pressure when it comes to using online shopping. 
Hedonic motivation was also not found to be a significant predictor of intention to use, and this could be explained by the fact that there are so many more interesting, engaging, and entertaining websites and apps on smartphones, so e-commerce websites do not have much hedonic motivation to offer, at least in the countries where higher bandwidth is easily available.

The current research indicates that habit is a significant predictor of intention to use for online shopping of both the products. However, habit was not found to be a significant indicator for use behavior, and this may be because habitual users are engaged in online activities and may have the intention to conduct online shopping, but just because they are highly engaged with online activities does not mean their frequent visits online will translate into a purchase decision. However, indirectly through intention to use, habit is a predictor of use behavior as well.

Businesses could target habitual users through advertising on online and offline channels by promoting usage contexts for airline tickets such as a summer vacation, weekend trip, returning home trip, and so forth. These users can also be a good target for the loyalty programs because they tend to be frequent visitors of online stores.

Performance expectancy was found to have a significant positive effect on intention to use for both the products. This reflects that users believe online shopping improves their performance because of it being useful, saving time for them, and so forth. Leveraging this finding, airline ticket companies could improve their services to make the online shopping experience more useful and convenient for the users by, for example, simplifying ticket purchases and payment processes further, providing intelligent and adaptive customer support, offering digital tickets, making their presence in social networking sites apparent, and using newer communication apps such as WhatsApp and LINE.
Trust, a popular research topic in the field of e-commerce, was found to be a significant predictor for both intention to use, and use behavior for both product categories. Factors such as the absence of common cyber laws, anxiety due to the absence of face-to-face interactions with the seller, and online frauds makes trust an important predictor of online shopping. Online sellers need to win the trust of their consumers by taking all the necessary steps to ensure the security of online transactions, protect customer information, and be quick and responsive in customer communication.

The main difference between the intention to use predictors for airline tickets and books is that the price value is one of the main user motivations behind online shopping for airline tickets, and LT was not found to be a significant construct. On the other hand, for books, LT was found to be a significant construct, and price value was not found to be a significant construct. This is because publishing and the book industry in Japan (Japan Book Publishers Association) has set the guidelines and policies for a fixed retail price of books. Detailed fieldwork was also conducted to compare the prices of books in the physical stores and online book stores in Japan, and it was found that there was no difference in the retail price of books between the two channels of sales. In this situation when the online retailers are not free to decide the pricing of their books, they are not able to pass on price benefits to consumers. Therefore, price value is not a significant construct for books in Japan. However, for airline tickets, price value is an important reason for selecting online shopping.

LT was found to have no significant relationship with intention to use for airline tickets. This may be because an airline ticket is not a physical product but is rather a service product. An airline ticket is just an information-based virtual product. There is not much difference in the number of products that could be purchased through online stores and brick-and-mortar stores because eventually brick-and-mortar stores 
also tend to use the Internet and airline system network to offer their services. Furthermore, there are no space constraints for the brick-and-mortar stores to limit the product offerings to a limited number of SKUs in the case of airline tickets as, even the brick-and-mortar stores use similar IT systems for reserving and selling airline tickets as the online stores. In this case, for airline tickets, LT was not found to be a significant construct behind user motivations for online shopping.

From the current research, we can conclude that the user motivations behind online shopping are different for different product categories. They are also influenced by external market situations, industry standards, and the inherent characteristics of the products.

In the current research, trust was validated to be an important factor behind user's intention to use and use behavior for online shopping. LT was also found to be a significant factor for physical products, but for the virtual products, it was not found to be a significant construct. Many prior studies have also emphasized the importance of trust behind user's intention to use and use behavior. The findings here propose the inclusion of trust and LT in an organized research framework such as UTAUT2 so as to subsequently arrive at a comprehensive research framework that could explain all the user motivations behind online shopping.

This study has some limitations as this research was conducted mainly in the urban areas of Japan, which have a high Internet penetration rate. In developing countries or even in the remote parts of Japan, the reasons behind online shopping may carry different weights. Also, the current research is focused on airline tickets and books, other products depending on their inherent characteristics, may have a different ranking of reasons for online shopping.

Future research could be conducted with additional constructs of trust and LT along with the UTAUT2 constructs for different products and in different geographical regions of the world. Also, the product characteristics related to the new construct could be tested to further understand the user motivations behind online shopping.

\section{Acknowledgement}

We would like to thank Prof. Tanabu Motonari (Yokohama National University, Japan) and Prof. Tsurumi Hiroyuki (Yokohama National University, Japan) for their valuable reviews and inputs in this research. Their constructive feedback at different stages of this research were very helpful.

We are also thankful to the respondents of the research questionnaire for their precious time and support to this research study.

\section{References}

Barrett, P. (2007). "Structural Equation Modelling: Adjusting Model Fit," Personality and Individual Differences, 42(5), pp. 815-824.

Brown, S. A., \& Venkatesh, V. (2005). "Model of Adoption of Technology in the Household: A Baseline Model Test and Extension Incorporating Household Life Cycle," MIS Quarterly, 29(4), pp. 399-426.

Brynjolfsson, E., Hu, Y., \& Simester, D. (2011). "Goodbye Pareto Principle, Hello Long Tail: The Effect of Search Costs on the Concentration of Product Sales," Management Science, 57(8), pp. 1373-1386.

Byrne, B. M. (1998). "Structural Equation Modeling with LISREL, PRELIS and SIMPLIS: Basic Concepts, Applications and Programming," Mahwah, New Jersey: Lawrence Erlbaum Associates. 
Childers, T. L., Carr, C. L., Peck, J., \& Carson, S. (2001). "Hedonic and Utilitarian Motivations for Online Retail Shopping Behavior," Journal of Retailing, 77(4), pp. 511-535.

Diamantopoulos, A., \& Signaw, J. A. (2000). Introducing LISREL. London: Sage Publications.

Dodds, W. V., Monroe, K. B., and Grewal, D. (1991). "Effects of Price, Brand, and Store Information on Buyers," Journal of Marketing Research, 28(3), pp. 307-319.

Escobar-Rodriguez, T., \& Carvajal-Trujillo, E. (2013). "Online Drivers of Consumer Purchase of Website Airline Tickets," Journal of Air Transport Management, 32, pp. 58-64.

Fornell, C., \& Larcker, D. F. (1981). "Evaluating Structural Equation Models with Unobservable Variables and Measurement Error," Journal of Marketing Research, 18, pp. 39-50.

Gefen, D., Karahanna, E., \& Straub, D. W. (2003). "Trust and TAM in Online Shopping: An Integrated Model," MIS Quarterly, 27(1), pp. 51-90.

Gefen, D., Straub, D. W., \& Boudreau, M. C. (2000). "Structural Equation Modeling and Regression: Guidelines for Research Practice," Communications of the Association for Information Systems, 4(7), pp. 1-70.

Hair, J. F., Black, W. C., Babin, B. J., \& Anderson, R. E. (2009). Multivariate Data Analysis $7^{\text {th }}$ Edition, Pearson.

Hong, I. B., \& Cha, H. S. (2013). "The Mediating Role of Consumer Trust in an Online Merchant in Predicting Purchase Intention," International Journal of Information Management, 33(6), pp. 927-939.
Hu, L. T., \& Bentler, P. M. (1999). "Cutoff Criteria for Fit Indexes in Covariance Structure Analysis: Conventional Criteria versus New Alternatives," Structural Equation Modeling, 6(1), pp. 1-55.

Internet World Stats. (2016). Retrieved from http://www.internetworldstats.com/stat s3.htm\#asia on December 15 ${ }^{\text {th }}, 2016$.

Limayem, M., Hirt, S. G., \& Cheung, C. M. K. (2007). "How Habit Limits the Predictive Power of Intentions: The Case of IS Continuance," MIS Quarterly, 31(4), pp. 705-737.

MacCallum, R. C., Browne, M. W., \& Sugawara, H. M. (1996). "Power Analysis and Determination of Sample Size for Covariance Structure Modeling," Psychological Methods, 1(2), pp. 130-149.

MacCallum, R. C., Roznowski, M., Corinne, M. M., \& Reith, J. V. (1994). "Alternative Strategies for CrossValidation of Covariance Structure Models," Multivariate Behavioral Research, 29(1), pp. 1-32.

Podsakoff, P. M., MacKenzie, S. B., Lee, J. Y., \& Podsakoff, N. P. (2003). "Common Method Bias in Behavioral Research: A Critical Review of the Literature and Recommended Remedies," Journal of Applied Psychology, 88(5), pp. 879-903.

Reichheld, F. F., \& Schefter, P. (2000). "ELoyalty: Your Secret Weapon on the Web," Harvard Business Review, 78(4), pp. 105-113.

Singh, M., \& Matsui, Y. (2015). "A Bibliometric Analysis on Online Shopping," International Journal of eEducation, e-Business, e-Management and e-Learning, 5(2), pp. 55-61.

Steiger, J. H. (2007). "Understanding the Limitations of Global Fit Assessment in Structural Equation Modeling," Personality and Individual Differences, 42(5), pp. 893-898. 
Swaminathan, V., Lepkowska-White, E., \& Rao, B. P. (1999). "Browsers or Buyers in Cyberspace? An investigation of Factors Influencing Electronic Exchange," Journal of Computer-Mediated Communication, 5(2), pp. 1-19.

Thong, J. Y. L., Hong, S. J., \& Tam, K. Y. (2006). "The Effects of Post-Adoption Beliefs on the ExpectationConfirmation Model for Information Technology Continuance," International Journal of Human-Computer Studies, 64(9), pp. 799-810.
Van der Heijden, H. (2004). "User Acceptance of Hedonic Information Systems," MIS Quarterly, 28(4), pp. 695-704.

Venkatesh, V., Morris, M. G., Davis, G. B., \& Davis, F. D. (2003). "User Acceptance of Information Technology: Towards a Unified View," MIS Quarterly, 27(3), pp. 425-478.

Venkatesh, V., Thong, J. Y. L., \& Xu, X. (2012). "Consumer Acceptance and Use of Information Technology: Extending the Unified Theory of Acceptance and Use of Technology," MIS Quarterly, 36(1), pp. 157-178. 


\section{Questionnaire: (Measurement Items only)}

\section{AIRLINE TICKET:}

PE1_AT. I think online shopping is useful for purchasing airline tickets.

PE2_AT. My productivity increases by using online shopping for purchasing airline tickets.

PE3_AT. Using online shopping for purchasing airline tickets helps me accomplish things more quickly in the purchasing process.

PE4_AT. I can save my time, when I use online shopping for purchasing airline tickets.

EE1_AT. Learning how to use online shopping for purchasing airline tickets is easy for me.

EE2_AT. My interaction with online shopping website for the purchase of airline tickets is clear and understandable.

EE3_AT. I find online shopping websites selling airline tickets, easy to use.

EE4_AT. It is easy for me to become skillful at using Online shopping for purchasing airline tickets.

SI1_AT. People who are important to me think that I should use online shopping for purchasing airline tickets.

SI2_AT. People who influence my behavior think that I should use online shopping for purchasing airline tickets.

SI3_AT. People whose opinions that I value prefer that I use online shopping for purchasing airline tickets.

FC1_AT. I have the resources necessary to use online shopping for purchasing airline tickets.
FC2_AT. I have the knowledge necessary to use online shopping for purchasing airline tickets.

FC3_AT. I feel comfortable using online shopping for purchasing airline tickets.

FC4_AT. I can get help from online customer support if I face any difficulty in using online shopping for purchasing airline tickets.

HM1_AT. Using online shopping for purchasing airline tickets is fun.

HM2_AT. Using online shopping for purchasing airline tickets is enjoyable.

HM3_AT. Using online shopping for purchasing airline tickets is very entertaining.

PV1_AT. I can save money by using online shopping for purchasing airline tickets by comparing the prices offered at different online stores.

PV2_AT. I like to search for cheap deals at different online stores when I purchase airline tickets through online shopping.

PV3_AT. I get good value for my money, if I do online shopping for purchasing airline tickets.

HT1_AT. Purchasing airline tickets through online shopping has become a habit for me.

HT2 AT. I am addicted to online stores for the purchase of airline tickets.

HT3_AT. I must use online shopping for purchasing airline tickets.

HT4_AT. Using online shopping for purchasing airline tickets has become natural to me.

IU1_AT. I intend to use online shopping for purchasing airline tickets in the future. 
IU2_AT. I will always try to use internet shopping for purchasing airline tickets.

IU3_AT. I plan to continue to use online shopping frequently for purchasing airline tickets.

TR1_AT. I trust the online store/website, from which I do online shopping for purchasing airline tickets.

TR2_AT. I believe, the online store/website will keep its promises and commitments when I purchase airline tickets through online shopping.

TR3_AT. I believe, the online store/website ensures security of my transaction, when I purchase airline tickets through online shopping.

TR4_AT. Based on my experience purchasing airline tickets from the online store/website in the past, I know online shopping is trustworthy.

LT1_AT. I can get more choices/options by purchasing airline tickets through online shopping.

LT2_AT. I can get broader selection, if I purchase airline tickets through online shopping.

LT3_AT. I can even purchase the airline tickets which are not available in the physical stores through online shopping.

UB_AT. In a year, on average how many times do you purchase airline ticket through online shopping.

\section{BOOK:}

PE1_B. I think online shopping is useful for purchasing books.

PE2_B. My productivity increases by using online shopping for purchasing books.

PE3_B. Using online shopping for purchasing books helps me accomplish things more quickly in the purchasing process.

PE4_B. I can save my time, when I use online shopping for purchasing books.

EE1_B. Learning how to use online shopping for purchasing books is easy for me.

EE2_B. My interaction with online shopping website for the purchase of books is clear and understandable.

EE3_B. I find online shopping websites selling books, easy to use.

EE4_B. It is easy for me to become skillful at using Online shopping for purchasing books.

SI1_B. People who are important to me think that I should use online shopping for purchasing books.

SI2_B. People who influence my behavior think that I should use online shopping for purchasing books.

SI3_B. People whose opinions that I value prefer that I use online shopping for purchasing books.

FC1_B. I have the resources necessary to use online shopping for purchasing books.

FC2_B. I have the knowledge necessary to use online shopping for purchasing books.

FC3_B. I feel comfortable using online shopping for purchasing books.

FC4_B. I can get help from online customer support if I face any difficulty in using online shopping for purchasing books.

HM1_B. Using online shopping for purchasing books is fun.

HM2_B. Using online shopping for purchasing books is enjoyable. 
HM3_B. Using online shopping for purchasing books is very entertaining.

PV1_B. I can save money by using online shopping for purchasing books by comparing the prices offered at different online stores.

PV2_B. I like to search for cheap deals at different online stores when I purchase books through online shopping.

PV3_B. I get good value for my money, if I do online shopping for purchasing books.

HT1_B. Purchasing books through online shopping is almost like a habit for me.

HT2_B. I am addicted to online stores for the purchase of books.

HT3_B. I must use online shopping for purchasing books.

HT4_B. Using online shopping for purchasing books has become natural to me.

IU1_B. I intend to use online shopping for purchasing books in the future.

IU2_B. I will always try to use internet shopping for purchasing books.

IU3_B. I plan to continue to use online shopping frequently for purchasing books.

TR1_B. I trust the online store/website, from which I do online shopping for purchasing books.

TR2_B. I believe, the online store/website will keep its promises and commitments when I purchase books through online shopping.

TR3_B. I believe, the online store/website ensures security of my transaction, when I purchase books through online shopping.
TR4_B. Based on my experience purchasing books from the online store/website in the past, I know online shopping is trustworthy.

LT1_B. I can get more choices/options by purchasing books through online shopping.

LT2_B. I can get broader selection, if I purchase books through online shopping.

LT3_B. I can even purchase the books which are not available in the physical stores through online shopping.

UB_B. In a year, on average how many times do you purchase books through online shopping.

\section{About the Authors}

Mahendra Singh has extensive experience in both corporate and academics area in Japan. $\mathrm{He}$ is a researcher and adjunct professor at Yokohama National University Japan, partner faculty at Globis University Japan, and adjunct professor at Sophia University Japan. He has corporate experience with companies such as Amazon, McKinsey \& Company, and Citibank in Japan. He completed his Ph.D. from Yokohama National University Japan, MBA from International University of Japan, and bachelor's degree from Indian Institute of Technology, Roorkee.

Yoshiki Matsui has extensive research and teaching experience in the area of Supply Chain Management, Production and Operations Management, and Technology Management. He is a professor at Graduate School of International Social Sciences, Yokohama National University, Japan. He has authored several books and research papers in reputed academic journals. 